\title{
Empirical Analysis of Determinants of Demand for Family Planning Services in Kenya's City Slums
}

\author{
Timothy C. Okech (Corresponding author) \\ United States International University \\ P.O. Box 14634, 00800, Nairobi, Kenya \\ Tel: 254-735-311-220_E-mail: tcokech@usiu.ac.ke; timkech@yahoo.com
}

\author{
Nelson W. Wawire \\ Kenyatta University, School of Economic \\ P.O Box 43844, 00100, Nairobi, Kenya \\ Tel: 254-722-347-139Ｅ-mail: nelsonwawire@yahoo.com
}

Tom K. Mburu

Kenyatta University, School of Economics

P.O Box 43844, 00100, Nairobi, Kenya

Tel: 254-722-931-783Ｅ-mail: mbukiwa@yahoo.com

Received: March 1, 2011 Accepted: March 15, 2011 doi:10.5539/gjhs.v3n2p109

\begin{abstract}
The purpose of the study was to empirically examine the determinants of demand for family planning services in Kenya's slums using a binomial logit model. The study revealed low usage of family planning services due to various factors. In order of significance, these include partner's approval, quality of the services, friendliness of the staff administering the services and the woman's knowledge about family planning services. Others were the woman's income level, proximity to the provider and the religious background of the woman. In lieu of the findings, various recommendations were suggested to enhance use of family planning services in the slums as a bold step towards enhance uptake of family planning services. Other than reviving and enhancing the activities of community based distributors, promotion of family planning education and activities at the household level should be carried out. Similarly, formation of lobby groups to enhance cultural change, as well as awareness creation and counselling, and integration of family planning services with HIV/AIDS were also been recommended.
\end{abstract}

Keywords: Family planning services, Unmet need, Contraceptive prevalence rate, Total fertility rate

\section{Introduction}

Many economies in the Sub-Saharan Africa (SSA) are characterized by rapid population growth. This according to Oyedokun (2007) is partly attributed to high fertility rate, high birth rates accompanied by steady declines in death rates, low contraceptive prevalence rate and high but declining mortality rate. In these countries, the rate of population growth is one of the highest in the world, estimated at 2.8 percent compared to the rest of the world (USAID/HPI, 2007). Equally, the number of people in need of health and education, among other public goods is large and increasing which in turn requires large amounts of resources, personnel and infrastructure. In response, many countries in SSA including Kenya have continued to focus their attention on birth control measures, especially the use of family planning services.

The government of Kenya recognized the importance of family planning soon after independence, and formally accepted population planning and family planning as part of the National Planning Strategies (Republic of Kenya, 1977). To enhance its commitment, the Government established the National Council for Population and Development (NCPD) whose mandate was to formulate population policies and strategies aimed at reducing the 
country's population growth rate. In 1994, the government formulated Kenya Health Policy Framework (KHPF) in which population development was identified as a strategy for achieving balanced socio economic development. Specifically, the Government prioritised reduction in fertility rate as well as increase in the proportion of health facilities providing integrated reproductive health services including family planning (FP) services as key priority. To reinforce its commitment further, the government launched Sessional Paper No. 1 of 1996 on National Population Policy for Sustainable Development, in which it recognized population challenges as unmet need for family planning and high level of adolescent fertility. In the Paper, the government reiterated its commitment to increasing availability, acceptability and affordability of quality family planning services by developing guidelines and standards for family planning service providers (Republic of Kenya, 1997).

The guidelines were not only developed to assist family planning providers in educating clients, but also to determine and provide the best method for clients' needs and to instruct the clients in the use of method and follow-up. In 1997, the government developed the Reproductive Health/Family Planning Policy Guidelines and Standards for Service Providers (Republic of Kenya, 1997) in which provision of quality and sustainable family planning services was identified as the main goal that would help to reduce the unmet needs for family planning. As part of its further commitment in addressing population growth, the Government in the National Health Sector Strategic Plan II (NHSSP-II) of 2005-2010 specified the Kenya Essential Health Package (KEPH) in which a wide range of population growth issues including family planning and child spacing were emphasised. The Government further reiterated its commitment in containing population growth in the Vision 2030 through various interventions including provision of family planning services (Republic of Kenya, 2007a).

\subsection{Trends in fertility rate and use of family planning services}

The policies developed by the government since 1965 remained dormant until the findings from the World Fertility Survey (WFS) in 1977 showed that Kenya had the highest fertility rates in the world estimated at 8 children per woman (Republic of Kenya, 2009). This statistic served to focus both policy and public attention on fertility issues and to reinvigorate the population policy, with the result that substantial national and international support was dedicated to developing and strengthening a vigorous national family planning programme. The impact of this was remarkable, as the fertility rate declined from 8.1 children per woman in 1977 to 6.7, 4.7 and 4.6 in 1989, 1998 and 2008 respectively (Republic of Kenya, 2003). Indeed, the decline in fertility between 1977 and 1998, from 8.1 to 4.7 births per woman was one of the most rapid declines ever documented in the world. This consistent decline in fertility led to projections that total fertility rate (TFR) would decline gradually to about 3.5 by 2008. This decline was attributed to increased contraceptive use among women aged between 15 and 49 year (Barasa and Kimani, 1991). On the other hand, the contraceptive prevalence rate increased rapidly from $9.7 \%$ in 1984 to $39 \%$ in 2003 . The sustained increase in the use of family planning services was a major factor in fertility transition, providing women and couples with the means to help them plan pregnancies. Indeed, when the results of the 1993 Demographic Health Survey (DHS) were released, Kenya's success in achieving a phenomenal decline in fertility was lauded globally, and many national and international observers felt that social norms in favour of small families and increased use of contraception were now well established and irreversible (Ian et. al., 2009). This reinforced the impression that the fertility transition in Kenya was well and truly established, and that the strategies that were being implemented and levels of funding available for both creating and supplying demand were appropriate for the country at this stage of fertility transition.

Consequently, the results of the 2003 DHS came as a shock to national and international observers and a flurry of activities ensued to try to "reposition" both family planning and population as key issues worthy of attention and investment. The government, for example replaced the NCPD with a National Coordinating Agency for Population and Development (NCAPD), and the Millennium Development Goals provided a platform for the role of population growth in sustainable development to be revisited and addressed. Many development partners have sought ways to increase their investments in support of family planning services, but their gradual disengagement over the previous decade meant that it was difficult to make convincing arguments to increase allocations for family planning in the face of other development challenges such as transportation, infrastructure, HIV/AIDS and education. Notwithstanding this, studies have however shown that, paradoxically it is the wealthier groups who benefit from government healthcare spending, not the poor (Sharma et. al. 2005a), (Sharma et. al. 2005b). Moreover, the poor may not be aware of policies designed to help increase access to reproductive healthcare services in general and family planning services in particular, such as user fee exemption schemes for the poor, or they may be subject to informal fees charged by providers.

\subsection{Statement of the problem}

From the foregoing discussion, it is clear that the Kenyan government has put in place various strategies and 
policies to facilitate the use of family planning services as a step towards reducing the fertility rates, increasing contraceptive prevalence rate (CPR) and reducing the unmet family planning needs. Despite these policy measures, total fertility rate still remains high at 4.6 percent, while CPR for all methods is at 46 percent. On the other hand, the unmet needs for family planning services average at 24 percent. The high TFR together with low CPR, unmet needs for family planning services, low death rate (estimated at 14.02 deaths per 1,000 women), high birth rate (estimated at 39.73 births per 1,000 population) and low infant mortality (estimated at 59.26 per 1000 live births) could be contributing towards high population growth (republic of Kenya, 2009)

Standards of living tend to worsen when the rate of population growth exceeds the rate of economic growth. At the household level, the high fertility rate may be contributing towards depletion of productive resources in the society, rising cost of living, ill health, poor nutrition and limited educational opportunities, ultimately trapping women in a poverty cycle. In the case of slums where poverty levels are high, the situation is likely to be worse. Although 2008 KDHS demonstrated that education, marital status, woman's income, and other demographic and socio-economic factors affect utilization of family planning services, the significance of these factors and provider factors have not been determined for the urban poor women living in the slums. The purpose of the study was to empirically examine the determinants of demand for family planning services by women in Kenya's slums using a binomial logit model.

\subsection{Overview of past studies.}

Various studies have been conducted with regard to the demand for health services in general and contraceptives in particular. In general, there are some aspects of the existing literature that deserve scrutiny. Most of these studies have used econometric tools that are inadequate in accounting for the complexity of relationships between family planning services due to the insufficiency of economic theory in the determination of the right specification. For instance, majority of the variables did not have a direct theoretical relationship, hence estimation could not have been plausible as it was done in the studies. Even there are a few studies that developed a theoretical model, all of them were concerned with the demand for health care and not family planning services. Similarly, none of the studies targeted respondents directly in the slums. This compares to the current study where respondents from the slums were targeted. At country level, although there exists a few studies regarding contraceptive use, most of them relied on secondary data from the demographic health surveys. The current study, however, went beyond by incorporating policy as well as demographic and socio-economic variable studies in order to examine how these variables influence the demand for family planning services in city slums.

In terms of variables considered, many of the studies were limited and relied heavily on descriptive statistics in the analysis. For instance, although the study by Clements and Nyovani in 2004 considered a wide variety of variables such as education level of both the woman and her partner, religion, partner's approval, marital status and age, no econometric model was adopted to examine the significant factors affecting demand for Family planning Services. Additionally, Clement and Nyovani (2004) did not undertake any statistical tests and identify key variables to be included in the study. This makes the study inadequate especially in the world of academic rigour. Like the case of Clements and Nyovani a study by Bertrand et al. (1995) considered many factors, some of which were incorporated in the current study. Bertrand et al. (1995) captured both the supply side as well as the demand side to evaluate family planning services. The current study only considered the demand side variables to avoid the economic problem of double causality. On the basis of the literature reviewed, various variables were found to affect demand for family planning services. This study considered some of these variables on a restrictive basis to examine how they affect demand for the services amongst the urban poor women living in city slums. It is worth noting that none of the studies reviewed targeted respondents in the city slums.

\section{Methodology}

In order to obtain the necessary data, the study adopted a survey design. The selection of the design was attributed to various reasons. First, it facilitated the collection of original data necessary to realize the research objectives. Secondly, it was also appropriate in collecting useful data that could be quantified and reported as a representation of the real situation or characteristic in the study population. The target populations were women in slums in the three cities of Nairobi, Mombasa and Kisumu identified through multistage sampling. The study relied on primary data collected using a structured interview schedule that contained both open ended and closed ended questions. Before collecting the necessary data, the instrument was pilot tested with a small representative sample. The pre-test of the instrument was necessary to find out if the tool could collect the necessary data to facilitate the realisation of the research objectives. This was because at a glance, it was not only possible to 
foresee all the potential misunderstandings or biasing effects of the questions but also to facilitate perfection of concept and wording. A code book was prepared for the various responses obtained. Thereafter, the data was cleaned to ensure completeness of the information before it was converted into the mode that could pick the necessary information. Various diagnostic tests including normality test, model specification and heteroskedasticity were undertaken on the specified model. A two-step regression analysis was done using STATA. The first step of analysis provided results in terms of probability, which could not be interpreted directly. As a result a second step was inevitable to convert the probabilities into marginal effects which were interpreted.

The model that was estimated was developed based on theory of consumer behaviour by first assuming that a woman faced information asymmetry and a variety of family planning services. In this case, the utility of a representative consumer (who in this case was a woman) was expressed as a function of observable attributes of family provider/facility, characteristics of the woman who intend to consume family planning services, and a random error. The amount of family planning services consumed was considered as an argument of a consumer's utility function. To avoid problems of measuring the amount of family planning services consumed, an indirect utility function of the following form was used.

$$
V_{i j}=V\left(P_{i j}, Y_{i}, S_{i}, F_{i j}, P_{o}\right)
$$

where $V_{i j}$ was indirect utility that consumer i derived from consuming family planning services $\mathrm{j}$, where $\mathrm{j}=1$, $2, \ldots, \mathrm{m}$; $\mathbf{P}$ was a vector of prices that consumer $i$ faced for the family planning services $j, Y_{i}$ was income of the consumer $\mathrm{i}$; $\mathrm{S}_{\mathrm{ij}}$ was personal characteristics of consumer $i$ like age, education, religion, and marital status, among others for family planning services $j$; $\mathbf{F}_{\mathbf{i j}}$ was facility/provider characteristics such as friendliness of staff at facility, perceived quality of the services and accessibility of the facility, among others that provide family planning services $j$, and $\mathrm{P}_{\mathrm{o}}$ was Government policies relating to family planning services such as promotion of family planning, among others. Given the choice model, it was necessary to invoke Roy's identity in order to obtain the amount of family planning services implied by the maximization of the indirect utility in equation (1). On the basis of this, a binomial logit model was estimated using a two-step regression technique. The binomial model estimated was of the form:

$$
\text { In }\{P / 1-P\}=\boldsymbol{X}_{i j} \boldsymbol{\beta}
$$

where $P$ was the probability of using any method of contraception. In this case, a consumer might be using or not using contraceptives; In is the natural logarithmic function, $\boldsymbol{\beta}$ is a vector of regression coefficients to be estimated; while $X_{i j}$ is a vector of explanatory variables that affect utilization of family planning services $j$ by household $i$. Based on the theoretical framework a functional equation was developed. The functional equation was of the form:

$$
U S f p=f(H H c r t, \text { Pfcrt, Govp })
$$

The dependent variable was the use of family planning services (USfp), while explanatory variables were characteristics of the woman (HHcrt); characteristics of the family planning services' provider (Pfpcrt); and government policies (Govp). These variables were chosen to reflect the factors that might be associated with family planning use in Kenya's city slums. The characteristics of the family planning services' providers and government policies were selected as indirect explanatory variables. The individual consumer characteristics included age (ag), number of living children (nlc), level of education (led), desire for children (dmc), marital status (mrts), partner's education (pted), approval by partner (pap), religious background of the woman (rlg) and average income of the woman (avinc). The characteristics of the family planning services' provider included quality of family planning services (qfps), proximity of the family facility (pxif) and friendly staff at facility (fsp). Government policies were restricted to promotion of family planning services (prfs) and user fees/price (pri). The restriction was necessary in order to limit the analysis on the knowledge of the woman regarding family planning services. Thus equation (3) was re-written as:

$$
\text { USfp }=f \text { (ag, nlc, pted, mrts, led, dmc, pap, rlg, avinc, qfps, pxif, fsp, prfs) }
$$

\subsection{Analysis of results}

In the model, use of family planning services was the dependent variable and was used as a proxy for demand for family planning services. This took the value of one (1) if family planning services were used at the time of survey and zero (0) if otherwise. The explanatory variables that were considered included age of the respondent, marital status, number of living children, average monthly income, educational level of the woman and partner, partners approval. Others were proximity of family planning provider, price of family planning services, knowledge of family planning services, availability of family planning services, friendliness of the staff, quality of family planning services and religion of the respondent. In order to determine the explanatory variables to use, 
correlation analysis was undertaken to establish the degree of correlation between the explanatory variables to avoid the problem of multicolinearity. Explanatory variables are however, rarely uncorrelated with each other and so multicolinearity is a matter of degree. The degree of correlation between the explanatory variable is presented in the appendices as appendix 1 . Various tests were also conducted on the model that was estimated. These included normality test, test for heteroskedasticity.

All the variables with a correlation of 0.50 and above were identified and only one of the variables selected for use in the regression. For instance, the degree of correlation between age of woman (age) and number of living children (nlc) was 0.64. Number of living children was picked and age of woman dropped from the regression. The correlation between proximity to the family planning facility and price of family planning services was -0.50 . Given that government health facility offers the services free of charge, proximity was considered an ideal proxy for price of family planning services. Partner's approval was preferred over availability of family planning services. The choice of the variable was also influenced by the fact that marital status and partner's education had a correlation of 0.50. Since partners approval is already included, it was ideal to include marital status. The explanatory variables that were finally included in the regression were income, proximity, marital status, female education, knowledge of family planning services, partner's approval, number of living children, religion, friendliness of staff and quality of family planning services. The results of the logistic regression are presented in table $\mathrm{A} 1$ in the appendices

As shown in table A1, all the coefficients of the explanatory variables had the expected sign except women education. Similarly, seven explanatory variables had coefficient that were statistically significant while the remaining three had coefficients that were statistically insignificant. The interpretation of the coefficient values was however, complicated by the fact that estimated coefficients from the model could not be interpreted as the marginal effect on the dependent variable. As a result, there was need to estimate the marginal effects as shown in table A2 in the appendices.

\subsection{Discussion of the findings}

As presented in table A2, all the explanatory variables had coefficients with expected signs except woman education, which was however shown to negatively influence the use of family planning. The coefficient of woman education was, however, not statistically significant at 1 percent as well as 5 percent or 10 percent level of significance. Seven variables, namely marital status of the woman, partner's approval, number of living children, quality of family planning services, friendliness of family planning services providers, proximity to the provider, income of the woman and knowledge of woman on family planning services had coefficients with positive signs that they increase the likelihood of the respondent using family planning services. On the other hand, religious background of the woman, proximity to the provider and education level of the woman had negative coefficients. The coefficients of religion and partner's approval were statistically significant at 1 percent whereas the coefficients of quality of family planning services, proximity to the provider and friendly staff at facility were statistically significant at 5 percent. On the other hand, the coefficients of income and knowledge of family planning were statistically significant at 10 percent level. Marital status and number of living children had coefficients that were not statistically significant at 1 percent as well as 5 percent and 10 percent.

The most important determinant of the likelihood of respondents in the slums using family planning services was partner's approval, whose marginal effect was 0.83 . This means that the probability of a respondent using family planning services was 83 percent where consent from partner was granted compared to where no consent was granted. The significance of this could be attributed to the fact that for a woman to use family planning services, partner's approval was critical. Otherwise if found using without the consent of partner it could be misinterpreted, thereby causing misunderstanding in a marriage. The second most important determinant was religion, which took the value of one if Catholic and zero, otherwise. The marginal effect was negative 0.28, implying that the probability of a woman using family planning services if she was a Catholic was 28 percent lower compared to others with different religious background such as Protestant and Muslims. This is because Catholic faith discourages faithfuls from using contraceptives as birth control measures. Faithfuls are instead encouraged to rely more on natural methods such as observation of menstruation cycles and natural safe days of a woman. This finding clearly indicates a significance difference in the use of family planning services between Catholics and other Religions.

Knowledge of family planning services was found to be the third most important determinant of likelihood of using family planning services with a marginal effect of 0.26 . The likelihood of using family planning services would be 26 percent higher for woman with knowledge of family planning services than those without. This clearly suggests that for increased uptake of family planning services, promotion that facilitates awareness about 
the available family planning services and their possible side effects and benefits is paramount. Friendliness of family planning staff had a marginal effect of 0.19 , implying that the likelihood of respondents using family planning services was 19 percent higher if family planning staff was friendly than when they were not. The significance of this determinant could be explained by the fact that provision of certain types of family planning services requires performance of some procedures by the person administering the services, for example injectables, hormone releasing implants and use of IUD.

With regard to quality of family planning services, the marginal effect was 0.17 . This implies that the probability of a woman using family planning services was 17 percent higher for respondents who perceived the services to be of high quality than for those who perceived otherwise. The positive impact of quality could be attributed to the fact that in the process of making a decision on using family planning services, perceived quality of the service is given a high consideration as supported by theory whereby taste and preference is an important factor in making demand decision. Proximity to family planning services provider had a marginal effect of negative 0.03, implying that the further away from the family planning services provider, the lower the likelihood of seeking the services by 3.3 percent. The negative impact of distance from the service provider could be attributed to the fact that when the provider is far away from the woman, there is bound to be some imbedded costs in terms of transport and transaction costs as well as waiting and travelling time, which may discourage a person from seeking the services. The last statistically significant variable was income, which had a marginal effect of 0.002, implying that an increase in average income of a woman by Kshs. 1,000 increased the likelihood of using family planning services by 2 percent.

Marital status and number of living children had each a marginal effect of about 0.02 , although they were statistically insignificant at 1 percent, 5 percent and 10 percent. The positive influence of marital status on the likelihood of using family planning services was attributed to the fact that couples might decide to postpone raising children by resorting to use of family planning services. The value of the marginal effect meant that a married woman is 2 percent more likely to use family planning services than a single woman. Finally, the positive influence of the number of living children on the likelihood of using family planning services could be attributed to the woman's desire for children having been satisfied.

\subsection{Conclusion}

In the study, Various facility factors were considered, among them quality of family planning services, availability of family planning services, proximity of the family planning facility and friendliness of staff. All explanatory variables positively influenced the usage of family planning services except religion and proximity to the family planning facility. In terms of statistically significance seven factors were significant while two were not. Among the statistically significant determinants of likelihood of usage of family planning services by order of their marginal effect were the partner's approval, religion, knowledge of family planning services, friendliness of family planning staff, quality of family planning services, proximity to the family planning facility and income. Regarding the explanatory power of the model, six eight percent of the variables included in the model explained the variation of the likelihood of the usage of family planning services. In the study, it was further established that even though key stakeholders involved in the provision of birth control measures especially family planning services, utilization of the same in the slums remains very low with only a few using the services. Various demographic, socio-economic and provider factors were found to empirically account for this. These include by order of their significance partner's approval, religion, knowledge of family planning services, friendliness of family planning staff, quality of family planning services, proximity to family planning facility and income. Thus, to enhance the uptake of family planning services as a bold step towards meeting the challenges envisaged in the Kenya's Vision 2030 and the realization of the MDGs, various recommendations were suggested for consideration.

First, there is need for the government through the relevant Ministries to revive and support family planning education at both household and community level that targets the woman and her partner. This could be undertaken through print and mass media, chiefs' barazas, market places as well as newsletters and posters. Additionally, the government through the Ministry of Health should encourage the uptake of family planning services at household level by enhancing continuous promotion of family planning services and provision of free condoms. This could be realised by supporting family planning outreach activities by the health workers. Enhancing standards and regulation to ensure that family planning services provided are of good quality is inevitable. Public health facilities may consider using revenue generated through facility improvement funds (FIF) to improve the quality of family planning services, including infrastructure, to encourage utilization of the services at facility level by the providers. 
Revamping and supporting Community Based Distribution of Family Planning services by the government, NGOs, and the CBOs is inevitable so that family planning services can reach the underserved in the slums. Lastly, the Ministry of Health in collaboration development partners involved in the provision of family planning services need to enhance large scale training of service providers in quality care, client follow up, communication skills, counselling, referral and feedback and provision of a wide choice of methods. This is because a majority of the respondents perceived the staff who administered family planning services as unfriendly. With good customer care, clients who seek family planning services will have confidence in the staff which in the process will attract more users while at the same time encouraging further usage on those currently using them. However, for this programme to be effective, donor support is critical. Creation of advocacy groups at community level is highly recommended. This will not only articulate the rights of the clients, in this case the woman who seeks family planning services, but will lead to cultural change towards family planning services and encourage the uptake of family planning services. In the end, this is expected to contribute positively towards a reduction in the total fertility rate as well as decline in population growth rate. NGOs, CBOs, and other institutions involved in family planning need to initiate and promote targeting programmes for the uptake of family planning services in the slums. Programs that aim at increasing the proportion of women using family planning are likely to be more effective in increasing the uptake of family planning services in the slums.

\section{References}

APHRC. (2001). Contraceptive Use Dynamics in Kenya Further Analysis of Demographic and Health Survey (DHS) Data, Nairobi, Kenya, Macro International Inc, Calverton, Maryland USA.

Barasa, J. \& S. Kimani. (1991). An Inventory of CBD Family Planning Services. Nairobi Kenya: National Council for Population and Development (NCPD) and United Nations Population Fund (UNFPA).

Bertrand, J. T., K. Hardee, R. J., Magnani, \& M. A., Angle. (1995). Access, Quality of Care and Medical Barriers in Family Planning Programs. International Family Planning Perspectives, 21 (2), 64-694. http://dx.doi.org/10.2307/2133525

Clement, S. \& S. Nyovani. (2004). Who Is Being Served Least by Family Planning Providers? A Study of Modern Contraceptive Use in Ghana, Tanzania and Zimbabwe. African Journal of Reproductive Health, 8 (2), 124-136. http://dx.doi.org/10.2307/3583186

David, E. B., David, C., \& Jaypee, S. (2002). The Demographic Dividend: A New Perspective on the Economic Consequences of Population Change, New York, Rand.

Feyisetan, B. J. \& S. Bamiwuye. (1998). Postpartum Counselling and Contraceptive Use in Nigeria. Ife Social Sciences Review, 15 (1), 30-41.

Hawkins, J., P. S. Matteson, \& E. S. Tabeek. (1995). A Fertility Control in Fogel, C. I. and N. F. Woods (Eds.), A Comprehensive Handbook. London, UK, Sage Publishers, Inc.

Health Policy Initiatives (HPI). (2007). Task Order 1. Inequalities in the Use of Family Planning and Reproductive Health Services: Implications for Policies and Programs, Washington DC, Futures Group International.

Ian, A., Alex, E., \& Bongaarts, J. Townsend. (2009). Kenya’s Fertility Transition, Determinants and Implications for Policy Programmes. Nairobi, Population Council.

Karirah-Gitau, Sarah (1999). Housing, Environment and Poverty Management in Eastern Africa, A Case of Slum Settlements in Nairobi, Kenya - A Final Report A Shelter Afrique Research Project funded by IDRC, Nairobi.

Kyalo, M. M. (1996). Determinants of Contraceptive Non-use in Kenya. MA Thesis, P. S. R. I., University of Nairobi, Kenya.

Lewis, M. A. (1986). Do Contraceptive Prices Affect Demand, Studies in Family Planning, 17 (3), 126-135. http://dx.doi.org/10.2307/1967030

Mason, A., D. B. Suits, \& M. Phananiramai. (1984). Fertility Decline in Four Asian Countries: How Important is Economic Development. Women in International Development, Working Paper no.53.

Mitullah, W. V. (1997). In-Depth Studies of Female Headed Households in Nairobi, Kibera. A Contribution to UNDP/UNIFEM/UNCHS Programme to Improve the Livelihoods of Female Headed Households Living in Informal Settlements.

Moreland, S. \& S. Talbird. (2006). Achieving the Millennium Development Goals: The Contribution of Fulfilling the Unmet Need for Family Planning. Washington, DC: Constella Futures, POLICY Project. 
Njogu, W. (1991). Trends and Determinants of Contraceptive Use in Kenya. Demography, 28 (1), 83-99. http://dx.doi.org/10.2307/2061337

Oyedokun, A. O. (2007). Determinants of Contraceptive Usage: Lessons from Women in Osun State, Nigeria, Journal of Humanities and Social Science, 1 (2).

Republic of Kenya. (1977). Kenya Fertility Survey 1977-1978. World Fertility Survey Programme, Nairobi, Government Printers.

Republic of Kenya. (1984). Kenya Contraceptive Prevalence Survey 1984. First Report. Ministry of Planning and National Development. Contraceptive Prevalence Survey Programme, Nairobi, Government Printer.

Republic of Kenya. (2003b). Demographic Health Survey of 2003, Nairobi, Government Printer.

Republic of Kenya. (2007a). National Reproductive Health Policy, Nairobi, Government Printer.

Republic of Kenya. (2007b). Kenya Vision 2030, the Popular Version, Nairobi, Government Printer.

Republic of Kenya. (2009). Demographic Health Survey of 2008, Nairobi, Government Printer.

Sharma, S., S. Smith, E. Sonneveldt, M. Pine, V. Dayaratnaya, \& R. Sanders. 2005b. Formal and Informal Fees for Maternal Health Care Services in Five Countries: Policies, Practices, and Perspectives. Washington, DC: Constella Futures, POLICY Project.

Sharma, S., S. Smith, M. Pine, \& W. Winfrey. (2005a). Formal and Informal Reproductive Healthcare User Fees in Uttaranchal, India. Washington, DC: Constella Futures, POLICY Project.

USAID/HPI. (2007). Achieving Equity for the Poor in Kenya: Understanding Level of Inequities and Barriers to Family Planning Services, Washington, DC.

World Bank. (1993). World Development Report 1993: Investing in Health, New York: Oxford University Press.

World Bank. (2003). World Development Report 2004: Making Services Work for Poor People, Washington, DC: World Bank.

\section{Appendix 1: Regression Results}

Table A1. Results of Logistic Regression Analysis

\begin{tabular}{|c|c|c|c|c|c|}
\hline Dependent Variable & \multicolumn{5}{|c|}{ Use of Family Planning Services } \\
\hline No. of Observations & \multicolumn{5}{|l|}{500} \\
\hline Explanatory Variable & Coefficient & $\mathrm{Z}$ & $\mathrm{P}>\mid \mathrm{z}$ & \multicolumn{2}{|c|}{ [95 percent Conf. Interval ] } \\
\hline Marital Status & 0.107 & 0.29 & 0.775 & -0.628 & 0.843 \\
\hline Religion & $-1.955^{*}$ & -5.24 & 0.000 & -2.685 & -1.224 \\
\hline Partners Approval & $7.362 *$ & 6.61 & 0.000 & 5.177 & 9.545 \\
\hline No. of living children & 0.119 & 0.97 & 0.332 & -0.122 & 0.361 \\
\hline Quality & 1.023* & 2.58 & 0.010 & 0.245 & 1.801 \\
\hline Proximity & $-0.221 *$ & -2.73 & 0.006 & -0.380 & -0.062 \\
\hline Friendly & $1.125 *$ & 2.56 & 0.010 & 0.264 & 1.985 \\
\hline Income & $0.011^{* *}$ & 2.01 & 0.045 & 0.000 & 0.023 \\
\hline Women Education & -0.003 & -0.05 & 0.958 & -0.130 & 0.125 \\
\hline Knowledge of FP & $1.369^{* *}$ & 2.22 & 0.026 & 0.162 & 2.575 \\
\hline $\mathrm{C}$ & -2.945 & -2.83 & 0.005 & -4.984 & $-0.906,-2.945$ \\
\hline Pseudo R2 & \multicolumn{5}{|c|}{0.6843} \\
\hline LR chi2(10) & \multicolumn{5}{|c|}{468.56} \\
\hline
\end{tabular}

* Imply significance at 1 percent level while ** imply significance at 5 percent level of significance 
Table A2. Results of Logistic Regression Analysis for Marginal Effects

\begin{tabular}{|l|l|l|l|l|l|l|l|}
\hline Dependent Variable & Use of Family Planning Services \\
\hline No. of Observations & 500 & \multicolumn{5}{|l|}{} \\
\hline Explanatory Variable & dy/dx & Std. error & Z & P $>|\mathrm{z}|$ & 95 percent Conf. Interval & $X$ \\
\hline Marital Status & 0.016 & 0.057 & 0.28 & 0.776 & -0.095 & 0.128 & 0.640 \\
\hline Religion & $-0.278^{*}$ & 0.086 & -3.25 & 0.001 & -0.446 & -0.110 & 0.556 \\
\hline Partners Approval & $0.829^{*}$ & 0.028 & 29.04 & 0.000 & 0.773 & 0.885 & 0.420 \\
\hline No of living children & 0.018 & 0.019 & 0.95 & 0.343 & -0.019 & 0.054 & 2.364 \\
\hline Quality & $0.166^{* *}$ & 0.079 & 2.08 & 0.037 & 0.009 & 0.322 & 0.622 \\
\hline Proximity & $-0.033^{* *}$ & 0.016 & -2.14 & 0.033 & -0.063 & -0.003 & 3.158 \\
\hline Friendly & $0.193^{* *}$ & 0.093 & 2.09 & 0.037 & 0.012 & 0.373 & 0.701 \\
\hline Income & $0.002^{* * *}$ & 0.001 & 1.74 & 0.081 & -0.001 & 0.004 & 24.824 \\
\hline Woman Education & -0.001 & 0.009 & -0.05 & 0.958 & -0.019 & 0.019 & 10.123 \\
\hline Knowledge of FP & $0.257^{* * *}$ & 0.139 & 1.85 & 0.064 & -0.015 & 0.529 & 0.806 \\
\hline
\end{tabular}

* Imply significance at 1 percent level while ${ }^{* *}$ and ${ }^{* * *}$ imply significance at 5 and 10 percent level of significance, respectively

\section{Appendix 2: Pairwise Correlation Matrix for Explanatory Variables}

\begin{tabular}{|c|c|c|c|c|c|c|c|c|c|c|c|c|c|c|}
\hline & Mstat & Price & Pappr & Age & Lchild & Quality & know & Proxity & DChild & Peduc & Relign & Wedu & Friend & Incm \\
\hline MStat & 1 & & & & & & & & & & & & & \\
\hline Price & 0.058 & 1.000 & & & & & & & & & & & & \\
\hline Pappr & 0.248 & 0.482 & 1.000 & & & & & & & & & & & \\
\hline Age & 0.354 & 0.077 & 0.060 & 1.000 & & & & & & & & & & \\
\hline LChild & 0.449 & 0.045 & 0.120 & 0.639 & 1.000 & & & & & & & & & \\
\hline Quality & -0.044 & 0.102 & 0.153 & -0.050 & -0.073 & 1.000 & & & & & & & & \\
\hline know & -0.057 & 0.051 & 0.599 & -0.060 & -0.114 & 0.186 & 1.000 & & & & & & & \\
\hline Proxity & -0.041 & -0.601 & -0.205 & 0.102 & 0.139 & -0.052 & -0.091 & 1.000 & & & & & & \\
\hline DChild & -0.045 & -0.060 & -0.130 & -0.162 & -0.109 & -0.021 & 0.038 & -0.050 & 1.000 & & & & & \\
\hline Peduc & 0.498 & 0.079 & 0.231 & 0.178 & 0.301 & -0.036 & -0.012 & -0.025 & -0.095 & 1.000 & & & & \\
\hline Relign & 0.019 & 0.063 & 0.057 & -0.034 & -0.043 & -0.015 & 0.001 & -0.137 & 0.028 & 0.071 & 1.000 & & & \\
\hline Weduc & 0.005 & -0.002 & 0.059 & 0.034 & -0.037 & 0.015 & -0.008 & 0.063 & -0.041 & 0.198 & -0.013 & 1.000 & & \\
\hline Frind & 0.041 & 0.220 & 0.248 & -0.021 & -0.040 & 0.200 & 0.223 & -0.241 & 0.066 & 0.027 & 0.074 & 0.044 & 1.000 & \\
\hline Incm & 0.231 & 0.780 & 0.117 & 0.247 & 0.215 & -0.007 & -0.054 & -0.002 & 0.610 & 0.613 & -0.052 & 0.097 & -0.051 & 1.000 \\
\hline
\end{tabular}

